\title{
openheart Environmental tobacco smoke and carotid intima-media thickness in healthy children and adolescents: a systematic review
}

\author{
Dingbo Shu, ${ }^{1,2}$ Feng Chen, ${ }^{3}$ Chuan Zhang, ${ }^{4}$ Wentong Guo, ${ }^{5}$ Siyu Dai (D) ${ }^{1}$
}

\begin{abstract}
- Additional supplemental material is published online only. To view, please visit the journal online (http://dx.doi.org/10. 1136/openhrt-2021-001790).
\end{abstract}

To cite: Shu D, Chen F, Zhang C et al. Environmental tobacco smoke and carotid intimamedia thickness in healthy children and adolescents: a systematic review. Open Heart 2022;9:e001790. doi:10.1136/ openhrt-2021-001790

5

DS and FC contributed equally.

DS and FC are joint first authors.

Received 18 July 2021

Accepted 29 November 2021

Check for updates

(C) Author(s) (or their employer(s)) 2022. Re-use permitted under CC BY-NC. No commercial re-use. See rights and permissions. Published by BMJ.

${ }^{1}$ School of Clinical Medicine, Hangzhou Normal University, Hangzhou, Zhejiang, China ${ }^{2}$ Zhejiang University Shaoxing Hospital, Shaoxing, Zhejiang, China

${ }^{3}$ Department of Paediatrics, The Chinese University of Hong Kong Faculty of Medicine, Hong Kong, China

${ }^{4}$ School of Physical Education and Sport, Central China Normal University, Wuhan, Hubei, China ${ }^{5}$ Department of Computer Science, City University of Hong Kong, Hong Kong, China

Correspondence to Dr Siyu Dai; daisiyu@hznu. edu.cn

\section{ABSTRACT}

Thicker carotid intima-media thickness (CIMT) has been a valid predictor for atherosclerosis development. A significant association between environmental tobacco smoke (ETS) and thickening of CIMT has been demonstrated in adults, whereas such association has scarcely been reviewed in paediatric population. The dominate electronic databases, including MEDLINE (Ovid), PubMed, Embase, CINAHL, Web of Science, Scopus, were searched from inception. Reference lists of retrieved articles were further scanned as to avoid any missing literatures. Newcastle-Ottawa scale was used to assess the quality of the included studies. Qualitative synthesis analyses were performed on the selected studies. 331 articles were retrieved, and 4 were finally selected. All four studies investigated the association between postnatal ETS and CIMT in children, and three of them reported a statistically significant positive association. Three studies investigated the association between prenatal maternal ETS and CIMT, and one of the three found a positive association. Two studies explored the association between postnatal maternal ETS and CIMT, one reported a positive association. Two studies used serum cotinine measurement to quantify ETS and demonstrated potential dose-response relationship with CIMT. ETS exposure may play an independent role in the development of cardiovascular risks in healthy children and adolescents. In the consideration of the great burden of respiratory and cardiovascular diseases, there is an urgent need of effective surveillance for paediatric population's ETS exposure to reduce smoke exposure.

\section{INTRODUCTION}

Although the adverse effect of environmental tobacco smoke (ETS) exposure on paediatric lung diseases has been well known, we are still at the initial phase of understanding the impact of ETS on paediatric antecedents of cardiovascular disease $(\mathrm{CVD}) .^{1-5}$ Several epidemiology and animal studies have explored the harm of ETS on cardiovascular system, including but not limited to platelet activation, inflammation, oxidation, endothelium dysfunction, changes in blood vessel stiffness and structures, as well as autonomic

\section{Key messages}

- Association between environmental tobacco smoke (ETS) and thickening of carotid intima-media thickness (CIMT) has been demonstrated in adults but has rarely been reviewed in paediatric population.

- Most of the included studies reported significant association between ETS exposure and thickening of CIMT in children and adolescents.

- In this systematic review a dose-response effect of ETS on CIMT was reported by the included studies when using cotinine as a biomarker for ETS.

- ETS exposure plays an important role in the development of cardiovascular risks in healthy children and adolescents.

- We strongly suggest surveillance for children's ETS exposure when considering the burden of cardiovascular and respiratory diseases.

- The findings are of great importance and could be used as an additional message to further motivate caregivers, especially smoking parents, in order to change their smoking habits and promote smokefree environment for their children.

dysfunction, and it has been found that ETS exposure has negative impact on these health outcomes. ${ }^{4-9}$ However, studies that directly assessed the relationship between ETS exposure and CVD health in children are scarce, and there is a lack of consensus regarding whether a direct link exists between them in paediatric population.

Atherosclerosis (AS) is a systemic CVD process characterised by the accumulation of fat deposit, inflammatory cell, as well as scar tissues within the arterial walls. ${ }^{10}$ In western countries, AS is the underlying cause of about $50 \%$ of all deaths, and tobacco utilisation is among the most important risk factors of AS development. Early AS is also known as subclinical AS, which is manifested as the thickening of the intima media of carotid arteries. Therefore, carotid intima-media thickness (CIMT) has been viewed as a good 
indication for the severity of subclinical AS. ${ }^{11}{ }^{12}$ It was proposed that for every $1 \mathrm{~mm}$ increase of CIMT, the HR would increase 2.46 times for cardiovascular events in. ${ }^{13}$ CIMT has been used as a valid and reliable marker for blood vessel changes and CVD risk estimation. ${ }^{14}$

Epidemiological studies found that ETS exposure is associated with thicker CIMT in adults. In addition, both prenatal and postnatal childhood ETS exposure has been proven to be linked with greater CIMT in adulthood. ${ }^{15-17}$ Despite the increasing evidence suggesting that vascular alterations may start from childhood in response to secondhand tobacco exposure, the relationship between ETS and CIMT has not been systematically reviewed in paediatric population. ${ }^{6}$ Filling this gap is of particular importance, as the American Heart Association (AHA) suggested that we still have insufficient knowledge about the linkage between ETS exposure and adverse cardiovascular health among youths, and further studies are warranted. ${ }^{718}$

It was pointed out that paediatric-specific health risks of ETS exposure might further motivate smokers to change their behaviours in order to protect the children. ${ }^{19}$ Therefore, information on how ETS may affect CVD-related health risks in children could be extremely valuable. Accordingly, we designed this systematic review to evaluate the relationship between ETS exposure and CIMT in healthy paediatric population. We hypothesised that ETS exposed healthy children and adolescents have thicker CIMT compared with their non-exposed peers.

\section{MATERIALS AND METHODS Systematic review}

A systematic review was performed to examine the relationship between passive smoke exposure and CIMT in healthy paediatric population by two independent reviewers (SDand DS). The methods and analysis of this systematic review were aligned with the Cochrane Handbook for Systematic Review ${ }^{20}$ as well as the Preferred Reporting Items for Systematic Reviews and Meta-analyses statement ${ }^{21}$ in online supplemental file B.

As parental smoking has been proven to be the major source of ETS exposure in children, and maternal smoking could show significant hazards on children's health, ${ }^{22-25}$ we aimed to address the following questions in this review study: (1) to examine whether prenatal maternal and parental smoking are associated with CIMT in healthy paediatric population, (2) to examine if postnatal maternal and parental smoking are associated with CIMT in healthy paediatric population and (3) to determine whether postnatal ETS exposure in general is associated with CIMT in healthy paediatric population. Qualitative analyses were carried out among selected articles, and we synthesised the results narratively.

\section{Literature search}

We systematically searched six major electronic databases from inception, which included MEDLINE (Ovid),
PubMed, Embase, CINAHL, Web of Science and Scopus, with the strategy of using keywords '(environmental tobacco smoke exposure OR second-hand smoke OR passive smoke OR involuntary smoke) AND (atherosclerosis OR carotid intima media thickness OR tunica intima)'. Related articles were identified up to $1 \mathrm{March}$ 2021. The search was limited to full-text English articles with participants under 18 years old. Reference lists of retrieved articles were further checked to avoid missing of any related articles.

\section{Study selection}

All articles searched were screened and extracted by two independent authors (SD and DS). Discussions were carried out to make the definitive decision where unanimous agreement could not be reached. Full-article review was performed under our predefined inclusion and exclusion criteria. Inclusion criteria is: (1) studies investigated the association between ETS exposure and CIMT in paediatric population. Exclusion criteria are: (1) review studies, editorials, letters or abstracts only; (2) the study was duplicated or ongoing research; (3) active smoking patients as the study sample and (4) patients having chronic diseases as the study sample.

\section{Outcome measure and data extraction}

The primary outcome was the relationship between ETS exposure and CIMT in paediatric population. Secondary outcome was the dose-response relationship between ETS exposure and CIMT. Data extracted were names of the authors, study title, publication date, research design, participant age, sex distribution, sample size, measurements of ETS exposure, measurements of CIMT, statistical analyses methods, point estimates together with their CIs of crude and adjusted effect sizes and adjustment levels.

\section{Assessment of the studies \\ Narrative synthesis}

Due to the high heterogeneity nature of study methodologies and limited number of yielded studies, it was impossible to perform formal meta-analysis. Thus, narrative syntheses were carried out. The current qualitative systematic review focused on (1) the population studied; (2) the types of ETS exposure and CIMT measurement and (3) results of the reported association.

\section{Quality assessment/risk of bias assessment}

Newcastle-Ottawa Scale (NOS) was used for the evaluation of study quality and risk of bias in this current review. ${ }^{26}$ NOS is one of the most commonly adopted tools used when assessing the quality of non-randomised studies included in a systematic review. NOS was chosen in the current study as opposed to other assessment tools, such as the NIH Quality Assessment Tool for Observational Cohort and Cross-Sectional Studies, as it is a standardised and quick tool in its application, and the assessed results of the involved studies could be compared readily in values. 


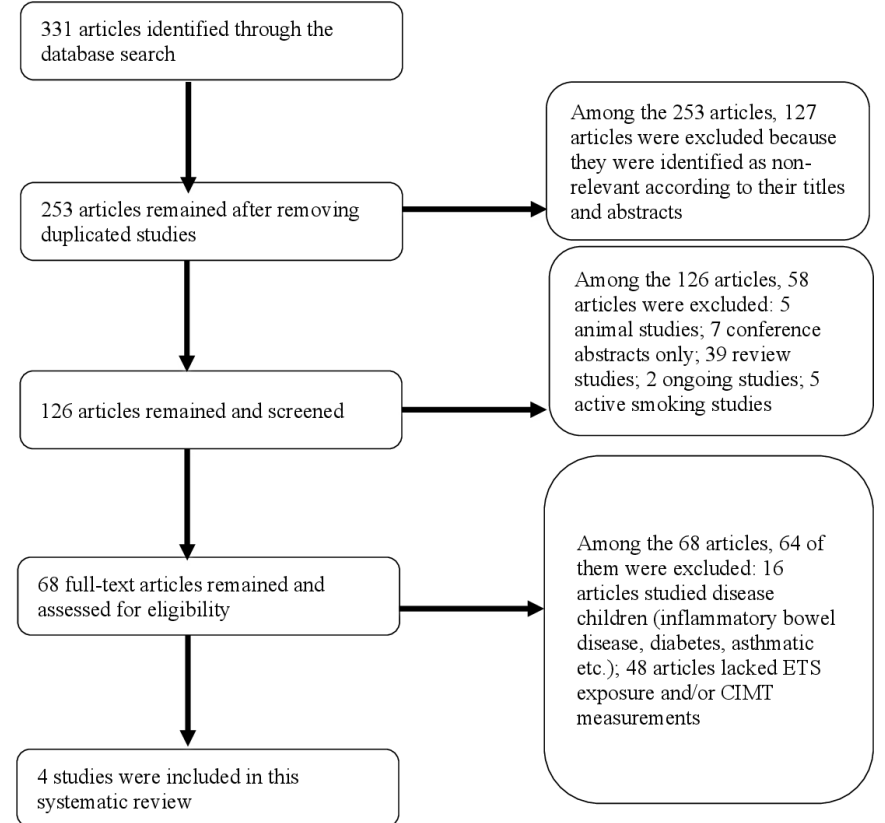

Figure 1 Flow diagram of the study selection. CIMT, carotid intima-media thickness; ETS, environmental tobacco smoke.

There are eight items of NOS scale which are categorised into three dimensions (selection, outcome and comparability). The highest score for each study is 9 points; $8-9$ points stands for very good quality; $6-7$ points stand for good quality; $4-5$ points stand for satisfactory quality; $0-3$ points stand for unsatisfactory quality (online supplemental file A).

\section{RESULTS}

\section{Search results}

A total of 331 related articles were retrieved in a combined search of the 6 electronic databases by following the abovementioned search method. After removing duplicated articles, 253 records remained for screening and selection, among which 127 articles were excluded because they were irrelevant according to the titles and abstracts. Among the remaining 126 articles, 58 records were further excluded for the following reasons: 39 were review studies; 5 were animal studies; 7 were conference abstracts without full text; 2 were ongoing studies and five were measuring active smoke exposure. Subsequently, 64 studies were further excluded for the following reasons: 16 articles studied diseased paediatric population such as children with inflammatory bowel disease diabetes and asthma; 48 studies were with insufficient information about ETS exposure and/or CIMT measurements. Finally, four articles were included in the current study (figure 1). ${ }^{2427-29}$

All included participants were healthy children and adolescents without cardiovascular risks, such as family history of CVD or obesity (table 1). Three out of the four studies recruited children from previous birth cohort, ${ }^{2427} 28$ while the only Asian study ${ }^{29}$ recruited adolescents prospectively (this study was initially designed to answer the current clinical questions). Among the 1782 participants involved in these four selected studies, $1197(67.2 \%)$ were boys and $585(32.8 \%)$ were girls. Participants aged from 5 to 16 years. There was no study recruited children younger than 5 years. Furthermore, two out of the four included studies ${ }^{24} 27$ provided data on children's gestational weeks, the majority of the children were full-term babies.

As for the assessment of children's ETS, generally prenatal maternal smoking was assessed by the delivery note or parental self-reported smoking condition during pregnancy, while the postnatal ETS condition was assessed by self-reported parental smoking conditions by using questionnaires and/or children's biochemical assessment of serum cotinine levels among the included studies (table 2). To be detailed, two studies assessed children's exposure by self-reported questionnaires (binary exposure condition, yes vs no), ${ }^{24} 27$ while the other two studies used objective serum cotinine level and classified exposure levels into low, medium and high according to different cut-off values. ${ }^{28}{ }^{29}$ In the study done by Kallio et $a l^{28}$ children's serum cotinine concentrations were measured repeatedly (2-6 times). The authors further divided the collected values into tertiles: low exposure group, the averaged cotinine values ranged from 0.1 to $0.4 \mathrm{ng} / \mathrm{mL}$; for intermediate group, the values ranged from 0.4 to $0.7 \mathrm{ng} /$ $\mathrm{mL}$; and for high exposure group, the values ranged from 0.7 to $4.1 \mathrm{ng} / \mathrm{mL} .^{28}$ In the study by Yang et al, ${ }^{29}$ the subjects were also divided into three groups by serum cotinine levels: for low exposure group, the mean cotinine level ranged from

\begin{tabular}{|c|c|c|c|c|c|c|c|c|c|}
\hline Study & Country & $\begin{array}{l}\text { Publication } \\
\text { year }\end{array}$ & Study design & Recruitment & $\mathbf{N}$ & $\begin{array}{l}\text { Age } \\
\text { (years) }\end{array}$ & $\begin{array}{l}\text { Male } \\
(\%)\end{array}$ & $\begin{array}{l}\text { Gestational } \\
\text { age (weeks) }\end{array}$ & Population \\
\hline Kallio et a ${ }^{28}$ & Finland & 2010 & Cross-sectional & $\begin{array}{l}\text { Recruited as infants in 1990- } \\
1992 \text { for the STRIP project }\end{array}$ & 494 & 13.0 & 52.4 & NA & Healthy children \\
\hline $\begin{array}{l}\text { Geerts et } \\
a l^{27}\end{array}$ & Netherlands & 2012 & Cross-sectional & $\begin{array}{l}\text { Recruited as infants in } 2001 \text { for } \\
\text { the WHISTLER project }\end{array}$ & 259 & $5.4 \pm 0.3$ & 43.6 & $\begin{array}{l}39.5 \pm 1.4 \\
(\text { mean } \pm S D)\end{array}$ & Healthy children \\
\hline Yang et $a P^{29}$ & China & 2011 & Cross-sectional & $\begin{array}{l}\text { Recruited through middle } \\
\text { schools in Lhasa city }\end{array}$ & 624 & 16.0 & 100.0 & NA & $\begin{array}{l}\text { Healthy } \\
\text { adolescents }\end{array}$ \\
\hline Ayer et $a p^{24}$ & Australia & 2011 & Cross-sectional & $\begin{array}{l}\text { Enrolled prior to birth into the } \\
\text { CAPS project in1997-1999 }\end{array}$ & 405 & 8.0 & 49.6 & $\begin{array}{l}39.6 \\
(39.4 \text { to } 39.7) \\
(95 \% \text { Cl })\end{array}$ & Healthy children \\
\hline
\end{tabular}

NA, not available; STRIP, Special Turku Coronary Risk Factor Intervention Project; WHISTLER, the WHeezing Illnesses STudy LEidsche Rijn. 
Table 2 Associations between ETS exposure and CIMT in children

\begin{tabular}{|c|c|c|c|c|}
\hline Study & ETS assessment & CIMT measurement & Exposure grouping & Main results \\
\hline $\begin{array}{l}\text { Kallio et al } \\
\text { Circa Cardiovasc Qual } \\
\text { Outcomes. } 2010^{28}\end{array}$ & $\begin{array}{l}\text { 1. Exposure of prenatal } \\
\text { maternal smoking: } \\
\text { Delivery records used; } \\
\text { 2. Postnatal any exposure: } \\
\text { biochemically } \\
\text { measured- annual } \\
\text { serum cotinine level } \\
\text { assessment during } \\
\text { 8-13 years }\end{array}$ & $\begin{array}{l}\text { 1. Method: Acuson } \\
\text { Sequoia } 512 \text { ultrasound } \\
\text { mainframe (Acuson) with } \\
\text { a 13.0-MHz linear-array } \\
\text { transducer } \\
\text { 2. Location: maximal CIMT- } \\
\text { the far (posterior) wall of } \\
\text { the distal common carotid } \\
\text { arteries 1-2 cm from the } \\
\text { bulb on both sides } \\
\text { 3. Single blind analysis }\end{array}$ & $\begin{array}{l}\text { (1) Prenatal maternal } \\
\text { smoking- three groups: } \\
\text { 5/160; } 7 / 171 ; 10 / 163 \\
\text { (2)Postnatal any exposure- } \\
\text { three groups } \\
\text { Low }(n=160) \text {; Intermediate } \\
\text { ( } n=171) ; \text { High ( } n=163) ; \\
\text { Average serum cotinine } \\
\text { (ng/ml): } 0.28(0.27-0.29) ; \\
0.52(0.51-0.53) ; 1.05 \\
(1.00-1.11) \text {, respectively }\end{array}$ & $\begin{array}{l}\text { (1) Between prenatal } \\
\text { maternal smoking and CIMT, } \\
\text { the association was not } \\
\text { significant: } \\
\text { Single determinant } \\
\text { regression coefficient: } \\
\text { pregnancy maternal smoke: } \\
\text {-0.004 } 0.013, \mathrm{p}=0.77 \\
\text { (2) Postnatal ETS exposure: } \\
\text { adolescents with higher } \\
\text { ETS exposure level } \\
\text { had thicker CIMT: CIMT } \\
\text { mean values by groups: } \\
\text { Low: } 0.502 \pm 0.079 \text { mm; } \\
\text { Intermediate, } \\
0.525 \pm 0.070 \mathrm{~mm} ; \text { High, } \\
0.535 \pm 0.066 \text { mm; } p<0.001 \\
\text { P values: Low vs intermediate } \\
0.013 ; \text { low vs high: }<0.001 ; \\
\text { intermediate vs high: } 0.57 ; \text { No } \\
\text { difference after adjustment }\end{array}$ \\
\hline $\begin{array}{l}\text { Geerts et al } \\
\text { Pediatrics. } 2012^{27}\end{array}$ & $\begin{array}{l}\text { 1. Exposure of prenatal } \\
\text { parental smoking: } \\
\text { parental self-reported } \\
\text { smoking condition by } \\
\text { questionnaire; } \\
\text { 2. Postnatal maternal } \\
\text { smoking: parental } \\
\text { self-reported } \\
\text { smoking conditions } \\
\text { by questionnaire at } \\
\text { children's } 5 \text { years old } \\
\text { 3. Postnatal paternal } \\
\text { smoking: parental } \\
\text { self-reported } \\
\text { smoking condition } \\
\text { by questionnaire at } \\
\text { children's } 5 \text { years old }\end{array}$ & $\begin{array}{l}\text { 1. Method: high-resolution } \\
\text { echo-tracking technology } \\
\text { (Art.laboratory) with a } \\
128 \text { radiofrequency line } \\
\text { multiarray and a L10- } \\
540 \mathrm{~mm} \text { linear array } \\
\text { transducer } \\
\text { 2. Location: maximal CIMT- } \\
\text { right common carotid } \\
\text { artery } \\
\text { 3. Single blind anlaysis }\end{array}$ & $\begin{array}{l}\text { (1) Prenatal maternal } \\
\text { smoking-two groups } \\
\text { Yes }(n=15) ; \text { No }(n=244) \\
\text { (2) Prenatal both parents } \\
\text { smoking-two groups } \\
\text { Yes ( } n=6) \text {; No (253) } \\
\text { (3)Postnatal any } \\
\text { exposure-two groups } \\
\text { Yes ( } n=49) ; \text { No }(n=210)\end{array}$ & $\begin{array}{l}\text { (1) ETS exposure in utero } \\
\text { could explain } 0.57 \text { SD of CIMT } \\
\text { Prenatal: pregnant women } \\
\text { smoking led to a } 0.0188 \mathrm{~mm} \\
\text { thicker CIMT in their offspring } \\
\text { ( } p=0.04 \text { ) } \\
\text { (2) The association between } \\
\text { ETS and CIMT was strongest } \\
\text { in children with both parents } \\
\text { smoking during pregnancy } \\
\text { (0.0277 mm thicker CIMT } \\
\text { compared with their non- } \\
\text { exposed peers) } \\
\text { Coefficient: crude: } 0.0154 \\
\text { (-0.02, } 0.0329), p=0.08 ; \\
\text { Mean CIMT (all children), mm: } \\
0.384 \pm 0.03\end{array}$ \\
\hline $\begin{array}{l}\text { Yang et al } \\
\text { J Renin-Angio-Aldo S. } 2012^{29}\end{array}$ & $\begin{array}{l}\text { (1) Postnatal any exposure: } \\
\text { biochemically assessment } \\
\text { of serum cotinine level }\end{array}$ & $\begin{array}{l}\text { 1. Method: High-resolution } \\
\text { B-mode carotid } \\
\text { ultrasonography (Vivid } \\
\text { 7) with a 7.5-MHz linear } \\
\text { transducer } \\
\text { 2. Location: maximal CIMT- } \\
\text { both sides of common } \\
\text { carotid artery proximal } \\
1 \mathrm{~cm} \text { to the bifurcation } \\
\text { 3. Single blind analysis }\end{array}$ & $\begin{array}{l}\text { (1) Postnatal any } \\
\text { exposure-three groups: } \\
\text { low }(n=209) \text {, intermediate } \\
\text { ( } n=210) \text {, high }(n=205) ; \text { By } \\
\text { averaged serum cotinine } \\
\text { ( } n g / \mathrm{mL})- \text { low: } 0.26-0.57 \\
(0.39 \pm 0.09) \text {; intermediate: } \\
0.58-0.89(0.74 \pm 0.11) ; \\
\text { high: } 0.90-1.14 \\
(1.00 \pm 0.08)\end{array}$ & $\begin{array}{l}\text { (1) The mean CIMT (mm) had } \\
\text { deteriorated in the high ETS } \\
\text { exposure group than the low } \\
\text { exposure group ( } p<0.001) \text {. } \\
\text { Low: } 0.62 \pm 0.08 \text {; Intermediate } \\
0.66 \pm 0.09 \text {; High: } 0.69 \pm 0.11 \text {; } \\
\text { P1 }<0.001 ; \mathrm{P} 2<0.001 \text {; } \\
\text { P3=0.0024 } \\
\text { P1: Comparison between low } \\
\text { and intermediate groups; P2: } \\
\text { Comparison between low and } \\
\text { high groups; P3: Comparison } \\
\text { between intermediate and } \\
\text { high groups }\end{array}$ \\
\hline
\end{tabular}


Table 2 Continued

\begin{tabular}{|c|c|c|c|c|}
\hline Study & ETS assessment & CIMT measurement & Exposure grouping & Main results \\
\hline $\begin{array}{l}\text { Ayer et al } \\
\text { European Heart Journal. } 2011^{24}\end{array}$ & $\begin{array}{l}\text { 1. Exposure of prenatal } \\
\text { maternal smoking: } \\
\text { parental self-reported } \\
\text { smoking conditions by } \\
\text { questionnaire } \\
\text { 2. Prenatal ETS exposure } \\
\text { except for maternal } \\
\text { smoking: questionnaire } \\
\text { filled by mother } \\
\text { 3. Postnatal any exposure: } \\
\text { home visit interview or } \\
\text { phone call }\end{array}$ & $\begin{array}{l}\text { 1. Method: high-resolution } \\
\text { ultrasound; } \\
\text { 2. Location: maximal CIMT } \\
\text { (Details not applicable) }\end{array}$ & $\begin{array}{l}\text { (1)Prenatal maternal } \\
\text { smoking-two groups: } \\
\text { Yes ( } n=93) \text {; No }(n=312) \\
\text { 1. Prenatal other } \\
\text { exposure-sample } \\
\text { number not found } \\
\text { 2. Postnatal any } \\
\text { exposure-sample } \\
\text { number not found }\end{array}$ & $\begin{array}{l}\text { (1) Prenatal maternal smoking: } \\
\text { Smoking in pregnancy: mean } \\
\text { CIMT (mm): } 0.59 \pm 0.06 \text {; No } \\
\text { smoking in pregnancy, mean } \\
\text { CIMT (mm): } 0.60 \pm 0.06 \text {, } \\
p=0.31 ; \text { CIMT mean difference } \\
(\mathrm{mm}): 0.008(0.007-0.02) \text {, } \\
p=0.31 \\
\text { (2) Postnatal maternal: } \\
0.59,0.60 \text {, difference: } 0.01 \\
(-0.02 \text { to } 0.03) \text {; } p=0.8 \text { (data } \\
\text { found in the article's online } \\
\text { supplemental material } \\
\text { Neither prenatal nor postnatal } \\
\text { passive smoke exposure was } \\
\text { linked to increase in CIMT }\end{array}$ \\
\hline
\end{tabular}

CIMT, carotid intima-media thickness; ETS, environmental tobacco smoke.

0.26 to $0.57 \mathrm{ng} / \mathrm{mL}$; for intermediate group, the level ranged from 058 to $0.89 \mathrm{ng} / \mathrm{mL}$ and for high exposure group, the level ranged from 0.9 to $1.14 \mathrm{ng} / \mathrm{mL}$.

In terms of the assessment of children's CIMT, all four selected studies used high-resolution ultrasound for the measurement (table 2). The measurement details are available from three out of the four studies. ${ }^{27-29}$ Among these three studies, the ultrasound equipment type was different. For the artery location of measurement, two studies detected common carotid arteries on both sides ${ }^{28} 29$ while one study detected right common carotid artery only. ${ }^{27}$ All the three studies conducted single blind analyses.

\section{Qualitative synthesis results}

To answer our research questions, among the included four studies: (1) Three studies examined the associations between prenatally maternal smoking and CIMT of. ${ }^{24} 2728$ One of them reported a statistically positive association. ${ }^{27}$ The other two studies reported non-significant results. ${ }^{24} 28$ (2) All four studies investigated the association between postnatal ETS exposure and CIMT in children. ${ }^{24} 2728$ Three studies $(75 \%)$ reported positive associations, ${ }^{27-29}$ while one study reported non-significant result. ${ }^{24}$ In summary, among these four studies, three of them found positive associations between ETS exposure and CIMT in children, but the reported exposure was different among studies. ${ }^{27-29}$ Furthermore, two studies that measured serum cotinine level in children demonstrated a significant association between ETS exposure and CIMT in a dose-response trend, which strengthened the potential causal relationship between ETS exposure and AS risk in paediatric population. ${ }^{28} 29$

Study methods and main findings of the selected four studies are summarised in table 2. There was significant heterogeneity among the four studies. The strengths and limitations of selected studies are summarised in table 3.

\section{Quality assessment/risk of bias assessment}

Three studies were not originally designed to answer the clinical question of whether ETS exposure was associated with higher AS risk; instead, they were retrospective studies by using data from subgroups. ${ }^{2427} 28$ The data were acquired from the participants of the WHeezing IIInesses STudy LEidsche Rijin (WHISTLER) Cardio study, ${ }^{27}$ the AS prevention trial Special Turku Coronary Risk Factor Intervention Project (STRIP), ${ }^{28}$ and the Sydney Childhood Asthma Prevention Study, ${ }^{29}$ respectively. We were unable to evaluate the potential influences of the original study design on associations between ETS exposure and CIMT. This issue of bias risk has been regarded as one of the most important components of epidemiological studies. ${ }^{30}$ Quality and the risk of bias varied among the four studies. In general, studies with higher quality are regarded to encounter lower risk of bias. According to NOS, only one study was estimated to have a high risk of bias, ${ }^{29}$ while the other three studies presented good study quality with data retrieved retrospectively, and two of the three reported statistically significant positive associations between ETS exposure and CIMT (table 4). ${ }^{24} 2728$

\section{DISCUSSION}

There are very limited number of Studies examining the relationship between ETS exposure and CIMT in paediatric population. The first epidemiological study was published in the year $2010 .^{28} \mathrm{Few}$ progresses on this research topic were made in the recent decade. ${ }^{8}$ After the comprehensive selection and narrative synthesis analyses, among the four selected studies, three of them $(75 \%)$ reported positive relationships between ETS exposure (though exposure periods are different) and CIMT. The results suggest that ETS exposure could be an independent risk factor for early onset of AS and atherosclerotic disease for healthy children 
Table 3 Strengths and limitations of selected studies

\begin{tabular}{|c|c|c|c|}
\hline Study & Strength & Limitation & Confounder adjustment \\
\hline $\begin{array}{l}\text { Kallio et al } \\
\text { Circa Cardiovasc } \\
\text { Qual Outcomes. } \\
2010^{28}\end{array}$ & $\begin{array}{l}\text { 1. ETS tested at multiple timepoints during } 8-13 \\
\text { years } \\
\text { 2. Objective biomarkers } \\
\text { 3. The first research: indicates that frequent ETS } \\
\text { exposure is related to thicker CIMT among } \\
\text { healthy } 13 \text {-year-old adolescents } \\
\text { 4. Interobserver variation reported } \\
\text { 5. Dose-response relationship investigated } \\
\text { 6. Measurements of other indexes such as FMD } \\
\text { and apolipoprotein }\end{array}$ & $\begin{array}{l}\text { 1. No information about the children's } \\
\text { exposure before the age of } 8 \text { years } \\
\text { 2. The possibility of having active } \\
\text { adolescent smokers among the } \\
\text { participants } \\
\text { 3. Retrospective ascertainment of } \\
\text { smoking in pregnancy (questionnaire) } \\
\text { 4. Potential residual confounding by } \\
\text { family SES, breastfeeding, pubertal } \\
\text { status }\end{array}$ & $\begin{array}{l}\text { Confounders used: } \\
\text { BMI, diastolic BP, sex, pubertal } \\
\text { status, STRIP study grouping } \\
\text { (intervention or control), ApoB, } \\
\text { ApoA-I, LDL cholesterol, and FMD }\end{array}$ \\
\hline $\begin{array}{l}\text { Geerts et al } \\
\text { Pediatrics. } 2012^{27}\end{array}$ & $\begin{array}{l}\text { 1. The first study investigates this relationship in } \\
\text { younger age group } \\
\text { 2. Comprehensive collection on exposure variables } \\
\text { including prenatal, perinatal and postnatal } \\
\text { period } \\
\text { 3. Able to distinguish the effect caused by prenatal } \\
\text { and postnatal exposure } \\
\text { 4. Dose-response relationship was investigated } \\
\text { 5. Cumulative exposure was measured } \\
\text { (questionnaire, amount and duration) }\end{array}$ & $\begin{array}{l}\text { 1. Self-reported exposure condition } \\
\text { 2. Slightly different demographic } \\
\text { characteristics between the prenatal } \\
\text { mother smoking group and non- } \\
\text { smoking group } \\
\text { 3. Small sample of smoking mothers with } \\
\text { limited statistical power } \\
\text { 4. Children's CIMT mean value was not } \\
\text { provided }\end{array}$ & $\begin{array}{l}\text { Two adjusted models: } \\
\text { 1. Age, sex, maternal age at birth } \\
\text { and breast feeding; } \\
\text { 2. Difference in BMl z-score } \\
\text { (BMl z-score at } 4 \text { weeks after } \\
\text { birth, and BMl z-score at the } \\
\text { children's age of } 5 \text { years) }\end{array}$ \\
\hline $\begin{array}{l}\text { Yang et al } \\
J \text { Renin-Angio- } \\
\text { Aldo S. } \\
2012^{29}\end{array}$ & $\begin{array}{l}\text { 1. Participants were randomly recruited from } \\
\text { school } \\
\text { 2. Exposure was measured by serum cotinine level } \\
\text { 3. Lipid profile was tested } \\
\text { 4. Active adolescent smokers were excluded } \\
\text { 5. Even participants with low exposure level were } \\
\text { shown to have thicker CIMT }\end{array}$ & $\begin{array}{l}\text { 1. Male sex only } \\
\text { 2. No non-exposed control group } \\
\text { 3. Hypoxia (in Tibet) is the risk factor of } \\
\text { AS } \\
\text { 4. One technician for the CIMT } \\
\text { measurement }\end{array}$ & No adjustment was made \\
\hline $\begin{array}{l}\text { Ayer et al } \\
\text { European Heart } \\
\text { Journal. } 2011^{24}\end{array}$ & $\begin{array}{l}\text { 1. ETS was measured at multiple timepoints: } \\
1 \text { year, } 5 \text { years, } 7.5 \text { years, etc. } \\
\text { 2. The first research: indicates the independent } \\
\text { role of prenatal ETS exposure on children's risk } \\
\text { of future CVD } \\
\text { 3. Detailed exposure condition was recorded in } \\
\text { each trimester }\end{array}$ & $\begin{array}{l}\text { 1. Exposure measured by questionnaire } \\
\text { (might underestimate the exposure } \\
\text { rate) } \\
\text { 2. Non fasting blood at } 8 \text { years. } \\
\text { 3. No further adjustment on ETS and } \\
\text { CIMT }\end{array}$ & $\begin{array}{l}\text { Since the mean CIMT was not } \\
\text { significantly different among } \\
\text { groups in univariate analysis } \\
\text { thus this study did not go for } \\
\text { multivariate adjustment }\end{array}$ \\
\hline
\end{tabular}

ApoA-I, apolipoprotein A; ApoB, apolipoprotein B; AS, atherosclerosis; BMI, body mass index; BP, blood pressure; CIMT, carotid intimamedia thickness; CVD, cardiovascular disease; ETS, environmental tobacco smoke; FMD, fibromuscular dysplasia; LDL, low-density lipoprotein; SES, socioeconomic status; STRIP, Special Turku Coronary Risk Factor Intervention Project.

and adolescents. However, more studies are strongly suggested to confirm this inference. Importantly, the quantum (amount) of exposure to smoke is the key to explore the relationship, as previous adult studies found that there was a significant increase in intima media thickness following more hours of passive smoke exposure ${ }^{15}$ which suggests a potential causal relationship between the exposure and CIMT in adults. Therefore, as children's exposure amount was insufficiently determined in these included studies, the interpretation of the results should be cautious. Additionally, only half of the included studies performed adjustment for the association calculations. ${ }^{27} 28$ Both of them adjusted for children's age and BMI; the first study also adjusted for children's pubertal status, STRIP study grouping (intervention or control), and other cardiovascular health indexes including diastolic blood pressure, apolipoprotein, apolipoprotein A, low-density lipoprotein (LDL) cholesterol and fibromuscular dysplasia; the second study did a relatively simple adjustment containing children's age, maternal age at birth and breastfeeding. What worth mentioning is that the adjustment among included studies may exert an impact on the results but does not alter the directions of the associations.

Our study provides evaluable information, and the key findings are important and might be used as additional message to further motivate caregivers, especially smoking parents, to change their smoking habits and promote smoke-free environment for their children. Childhood is a critical window for vascular system development, and it has been strongly suggested that vascular cell growth and some signal pathway could be more vulnerable to the hazards caused by ETS during this period. ${ }^{6}$ The damaged vascular system of children could show systemic and lifelong impact. ${ }^{7}$ 


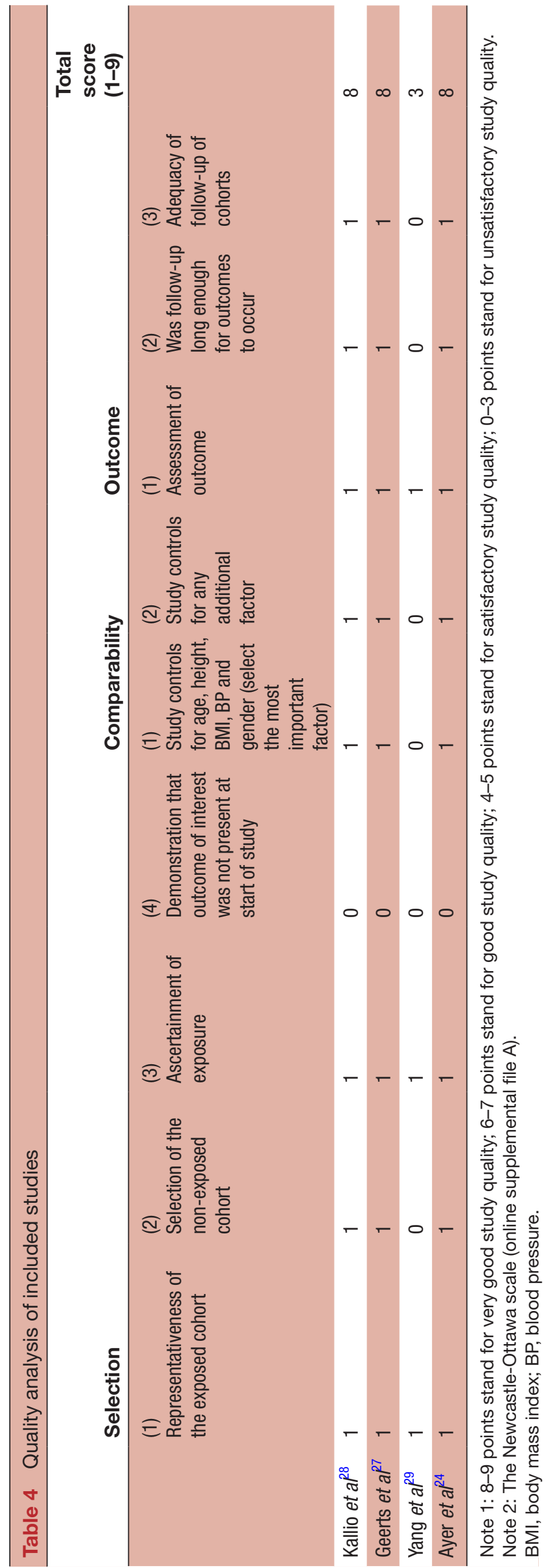

\section{ETS exposure and CIMT in children}

In this systematic review, most of the included articles showed significant positive associations between ETS exposure and CIMT in children except for the one by Ayer et al, which reported negative associations. ETS exposure was studied as a potential confounder when assessing the impact from prenatally maternal smoking, but the association did not remain significant in the final multivariate analysis model. ${ }^{24}$

Studies on adults showed that for every one $\mathrm{mm}$ increase of CIMT, the HR for cardiovascular events increases by 2.46 times. ${ }^{13}$ Scholars have previously demonstrated that the adverse cardiovascular effects of ETS exposure are as large as active smoking. ${ }^{9}$ The toxicity of ETS on children's cardiovascular system has been suggested in the 2006 US surgeon report and was later comprehensively summarised in the 2016 AHA review. ${ }^{16}$ ETS exposure has been proven to be related with reduced nitric oxide bioavailability and endothelial damage which result in endothelial dysfunction, and it is likely to increase arterial stiffness and blood pressure. Furthermore, ETS exposure is linked to elevated levels of inflammatory cytokines, increased LDL deposition, reduced oxidation defence and reduction in high density lipoprotein (HDL) levels. ${ }^{31-33}$ ETS components may also have direct toxic impacts on individual's endothelium permeability and structure and enhance platelet activation. Those alterations allow the smoke constituents to bind to the blood vessel's injured areas and accelerate smooth muscle cells' growth. Furthermore, the exposure may increase the lipid peroxidation level and accelerate the macrophages' uptake of LDL cholesterol. All these processes might accelerate the development of AS.

The severity of the adverse effects caused by ETS exposure on vascular system may depend on the exposure dosage, which has been commonly determined by the following items: the length of exposure time, the exposure intensity, the ageing of the ETS constituents, or the children's race and age. ${ }^{6}$ The changes of key components of passive smoke induced biomarker have been linked to specific cardiovascular impact. For instance, nicotine has been reported to be linked with haemodynamic alterations; acrolein has been found to be associated with oxidative stress, inflammation and atherogenesis; crotonaldehyde has been found to be associated with plaque instability and thrombosis, and lead is linked with the risk of hypertension. ${ }^{634}$ Animal studies have explored the possible mechanisms and suggested that early-life ETS exposure would increase AS lesions later in life. ${ }^{6}$ Inferred mechanisms include elevated oxidative stress, proinflammatory impacts, mitochondrial damage and reduced endothelial function. Tani et al have documented the increased CIMT in ETS exposed mice compared with non-exposed ones. ${ }^{35}$

\section{Prenatal exposure}

Two of the included studies explored the relationships between prenatal exposure and CIMT. ${ }^{24}$ There was 
difficulty in isolating the influences of prenatal ETS exposure on childhood cardiovascular health from other postnatal (especially environmental) factors. One of the previous studies indicates that pregnancy would be the critical window for the ETS associated vascular damage to occur. ${ }^{27}$ However, other studies did not report a similar relationship. Notably, one study reported inconsistent results that positive relationship was found between ETS exposure and vascular damage in younger children (about 5 years) compared with those studies reporting no significant associations (16 and 13 years). The disparities in study methodologies, such as the exposure measurements and health outcome measurement, may also partly account for the result variations. Interestingly, the prenatally maternal smoking rate in the study with positive findings was lower than the other two studies $\left(5.8 \%{ }^{27}\right.$ vs $7.3 \%^{28}$ and $23.0 \%{ }^{24}$ ), which imply that the age at CIMT measurement is a potentially significant factor to be taken into consideration. It is possible that as children grow older, their developing system may be able to repair the vascular damage caused by prenatal ETS exposure. More studies are needed to confirm this inference. In addition, the insufficient adjustment for confounding variables may explain the lack of significance between ETS exposure and CIMT in some studies. More longitudinal studies are strongly recommended to evaluate the impact of prenatal ETS exposure on the long-term cardiovascular health in children and adolescents.

The mechanism of the impact of prenatally maternal smoking on children's vascular health could be different from postnatal ETS exposure. Nicotine can pass through the placenta, and it has been addressed by scholars that the concentration of cotinine in neonate could be equal to the level of the smoking mother. ${ }^{36}$ It was suggested that smoking during pregnancy would induce chronic hypoxia by carbon monoxide and decrease nitric oxide generation in their fetuses. ${ }^{37}$ It was reported that mothers' tobacco utilisation would result in a different (para) sympathetic control in their babies. ${ }^{38}$ This alteration leads to the disparities of vascular physiology between ETS-exposed infants and their non-exposed peers. ${ }^{38}$ Last but not least, the potential insufficient adjustment for confounders in some studies may mask the significant relationship between ETS exposure and CIMT, making it hard to draw definitive conclusions from these studies. Therefore, further studies with comprehensive evaluation for potential confounding variables are needed.

\section{Potential mechanism}

ETS exposure has been proven to affect several biological processes related to AS: reduced nitric oxide bioavailability and endothelial damage resulting in endothelial dysfunction; increase in brachial and systolic blood pressure resulting in increased arterial stiffness. ETS exposure promotes elevated levels of inflammatory cytokines. It has also found to be associated with increased LDL deposition, reduced oxidation defence and reduction in HDL level. ${ }^{33}$ However, the specific mechanism of how ETS exposure links to CIMT thickening has not been clearly elucidated yet.
It has been reported that ETS can affect the activation of platelets leading to their recruitment, adherence, and migration to the endothelium in adults. ${ }^{39}$ However, as children and adolescents are in the critical window of physical development, the ability of the vascular system of children is quite different when compared with that of adults, such as the weaker detoxification ability as well as the reversion of vascular damage. ${ }^{40}$ Further studies to confirm the associations between ETS exposure and early vascular damage in children are important, as early surveillance and intervention for children's ETS exposure could potentially decrease the future healthcare burden from CVD. Future study directions also include the exploration of the mechanism causing the harmful effects.

\section{Strengths and limitations}

The current systematic review focused on healthy paediatric population without previous cardiovascular risks. Our pooled study results provided further evidence that ETS exposure might play an independent role in the development of atherosclerotic changes in childhood. Nonetheless, there are several limitations regarding this systematic review.

First, there was limited number of studies that could be included in this review, thus it was challenging to draw conclusions, and the pooled results should be interpreted with caution. First, caution should be specially applied to the associations between different quantum of exposure and thickening of CIMT, as it is unclear how exposure time length and dosage is associated with the risk of CVD in children. Second, due to the heterogeneity among the study methodologies, we could not perform meta-analysis to quantitatively evaluate the issue. In addition, the different methods employed for ETS measurement may partly explain the controversial findings among different studies. Last, the gestational period (term, pre-term) can be an important predictor for children's cardiovascular health, while none of the included studies adjusted children's gestational condition when performing the association calculations.

\section{CONCLUSIONS}

This systematic review explored the associations between ETS exposure and CIMT in healthy paediatric population. We found that ETS exposure might be associated with vascular structure damage among healthy children and adolescents, and the identified dose-response relationships further strengthened the potential causal relationship. However, available studies are limited, and longitudinal studies are strongly recommended. A more ideal epidemiologic study would be of prospective follow-up study design with larger sample size, and annual assessment on ETS (self-reported measures for long-term exposure, urinary/serum cotinine for short-term exposure) and CIMT should be carried out. Our results may offer new insights for AS prevention and contribute to the field of tobacco control in paediatric population. With the high prevalence of ETS and the great burden of CVD, 
there is an urgent need of surveillance for children's ETS exposure in order to reduce ETS exposure.

Contributors This paper is the result of teamwork. The study was conceived of, designed by and critically revised by SD. DS and FC contributed equally to drafting the manuscript. CZ and WG offered advice on the workflow and critically revised the manuscript. All authors have read and agreed to the published version of the manuscript.

Funding The authors have not declared a specific grant for this research from any funding agency in the public, commercial or not-for-profit sectors.

Competing interests None declared.

Patient consent for publication Not applicable.

Provenance and peer review Not commissioned; externally peer reviewed.

Data availability statement All data relevant to the study are included in the article or uploaded as online supplemental information.

Open access This is an open access article distributed in accordance with the Creative Commons Attribution Non Commercial (CC BY-NC 4.0) license, which permits others to distribute, remix, adapt, build upon this work non-commercially, and license their derivative works on different terms, provided the original work is properly cited, appropriate credit is given, any changes made indicated, and the use is non-commercial. See: http://creativecommons.org/licenses/by-nc/4.0/.

ORCID iD

Siyu Dai http://orcid.org/0000-0001-9320-689X

\section{REFERENCES}

1 US Department of Health and Human Services. The health consequences of involuntary exposure to tobacco smoke: a report of the surgeon General. Atlanta, GA: U.S. Department of Health and Human Services, Centers for Disease Control and Prevention, Coordinating Center for Health Promotion, National Center for Chronic Disease Prevention and Health Promotion, Office on Smoking and Health, 2006.

2 McEvoy CT, Spindel ER. Pulmonary effects of maternal smoking on the fetus and child: effects on lung development, respiratory morbidities, and life long lung health. Paediatr Respir Rev 2017;21:27-33.

3 Jones LL, Hashim A, McKeever T, et al. Parental and household smoking and the increased risk of bronchitis, bronchiolitis and other lower respiratory infections in infancy: systematic review and metaanalysis. Respir Res 2011;12:5-15.

4 Gidding SS, Schydlower M. Active and passive tobacco exposure: a serious pediatric health problem. Pediatrics 1994;94:750-1.

5 Leonardi-Bee J, Smyth A, Britton J, et al. Environmental tobacco smoke and fetal health: systematic review and meta-analysis. Arch Dis Child Fetal Neonatal Ed 2008;93:F351-61.

6 Raghuveer G, White DA, Hayman LL, et al. Cardiovascular consequences of childhood secondhand tobacco smoke exposure: prevailing evidence, burden, and racial and socioeconomic disparities: a scientific statement from the American heart association. Circulation 2016;134:e336-59.

7 Steinberger J, Daniels SR, Hagberg N, et al. Cardiovascular health promotion in children: challenges and opportunities for 2020 and beyond: a scientific statement from the American heart association. Circulation 2016;134:e236-55.

8 Juonala M, Magnussen CG, Raitakari OT. Parental smoking produces long-term damage to vascular function in their children. Curr Opin Cardiol 2013;28:569-74.

9 Tanski SE, Wilson KM. Children and secondhand smoke: clear evidence for action. Pediatrics 2012;129:170-1.

10 Lusis AJ, Aldons JL. Atherosclerosis. Nature 2000;407:233-41.

11 Feinstein SB, Voci P, Pizzuto F. Noninvasive surrogate markers of atherosclerosis. Am J Cardiol 2002;89:31-43.

12 Roger VL, Go AS, Lloyd-Jones DM, et al. Heart disease and stroke statistics--2011 update: a report from the American Heart Association. Circulation 2011;123:e18-209.

13 Polak JF, Pencina MJ, Pencina KM, et al. Carotid-wall intimamedia thickness and cardiovascular events. N Engl J Med 2011;365:213-21.

14 Doyon A, Kracht D, Bayazit AK, et al. Carotid artery intima-media thickness and distensibility in children and adolescents: reference values and role of body dimensions. Hypertension 2013;62:550-6.
15 Howard G, Burke GL, Szklo M. Active and passive smoking are associated with increased carotid wall thickness. The Atherosclerosis risk in Communities study. Arch Intern Med 1994;154:1277-82.

16 Geerts CC, Bots ML, Grobbee DE, et al. Parental smoking and vascular damage in young adult offspring: is early life exposure critical? the Atherosclerosis risk in young adults study. Arterioscler Thromb Vasc Biol 2008;28:2296-302.

17 Gall S, Huynh QL, Magnussen CG, et al. Exposure to parental smoking in childhood or adolescence is associated with increased carotid intima-media thickness in young adults: evidence from the cardiovascular risk in young finns study and the childhood determinants of adult health study. Eur Heart J 2014;35:2484-91.

18 Farber HJ, Groner J, Walley S, et al. Protecting children from tobacco, nicotine, and tobacco smoke. Pediatrics 2015;136:e1439-67.

19 Rosen LJ, Noach MB, Winickoff JP, et al. Parental smoking cessation to protect young children: a systematic review and meta-analysis. Pediatrics 2012;129:141-52.

20 Higgins JP, Wells GA. Cochrane Handbook for systematic reviews of interventions 2011.

21 Moher D, Liberati A, Tetzlaff J, et al. Preferred reporting items for systematic reviews and meta-analyses: the PRISMA statement. Ann Intern Med 2009;151:264-9.

22 Farber HJ, Walley SC, Groner JA, et al. Clinical practice policy to protect children from tobacco, nicotine, and tobacco smoke. Pediatrics 2015;136:1008-17.

23 Juonala M, Magnussen CG, Venn A, et al. Parental smoking in childhood and brachial artery flow-mediated dilatation in young adults: the cardiovascular risk in young finns study and the childhood determinants of adult health study. Arterioscler Thromb Vasc Biol 2012;32:1024-31.

24 Ayer JG, Belousova E, Harmer JA, et al. Maternal cigarette smoking is associated with reduced high-density lipoprotein cholesterol in healthy 8-year-old children. Eur Heart J 2011;32:2446-53.

25 Berlin I, Oncken C. Maternal smoking during pregnancy and negative health outcomes in the offspring. Nicotine Tob Res 2018;20:663-4.

26 Wells GA, Shea B, O'Connell D, et al. The Newcastle-Ottawa scale (NOS) for assessing the quality of Nonrandomised studies in metaanalyses. Ottawa: The Ottawa Hospital, 2021.

27 Geerts CC, Bots ML, van der Ent CK, et al. Parental smoking and vascular damage in their 5 -year-old children. Pediatrics 2012;129:45-54

28 Kallio K, Jokinen E, Saarinen M, et al. Arterial intima-media thickness, endothelial function, and apolipoproteins in adolescents frequently exposed to tobacco smoke. Circ Cardiovasc Qual Outcomes 2010;3:196-203.

29 Yang B, Li M, Chen B, et al. Deterioration of endothelial function and carotid intima-media thickness in Tibetan male adolescents exposed to second-hand smoke. J Renin Angiotensin Aldosterone Syst 2012;13:413-9.

30 Zou B, Wilson JG, Zhan FB, et al. Air pollution exposure assessment methods utilized in epidemiological studies. J Environ Monit 2009;11:475-90.

31 Spear C, Raghuveer G. Lifelong cardiovascular adverse effects of childhood tobacco smoke exposure. Curr Cardiovasc Risk Rep 2016;10:26

32 Messner B, Bernhard D. Smoking and cardiovascular disease: mechanisms of endothelial dysfunction and early atherogenesis. Arterioscler Thromb Vasc Biol 2014;34:509-15.

33 DiGiacomo S, Jazayeri M-A, Barua R, et al. Environmental tobacco smoke and cardiovascular disease. Int J Environ Res Public Health 2019;16:96.

34 Ramond A, Gregson J, Willeit P. Environmental toxic metal contaminants and cardiovascular risk: a systematic review and meta-analysis of observational studies. BMJ 2018;362:k3310.

35 Tani S, Dimayuga PC, Anazawa T, et al. Aberrant antibody responses to oxidized LDL and increased intimal thickening in apoE-/- mice exposed to cigarette smoke. Atherosclerosis 2004;175:7-14.

36 Yang J, Pearl M, Jacob P, et al. Levels of cotinine in dried blood specimens from newborns as a biomarker of maternal smoking close to the time of delivery. Am J Epidemiol 2013;178:1648-54.

37 Jaddoe VWV, de Ridder MAJ, van den Elzen APM, et al. Maternal smoking in pregnancy is associated with cholesterol development in the offspring: a 27 -years follow-up study. Atherosclerosis 2008:196:42-8

38 Milei J, Ottaviani G, Lavezzi AM, et al. Perinatal and infant early atherosclerotic coronary lesions. Can J Cardiol 2008;24:137-41.

39 Rubenstein D, Jesty J, Bluestein D. Differences between mainstream and sidestream cigarette smoke extracts and nicotine in the activation of platelets under static and flow conditions. Circulation 2004;109:78-83. 
40 Celermajer DS, Ayer JGJ. Childhood risk factors for adult

$2006 ; 92: 1701-6$ cardiovascular disease and primary prevention in childhood. Heart 